\title{
Stuffed Pants! Staging Full-scale Comic Plays with Students of Italian as a Foreign Language
}

\section{Filippo Fonio}

\begin{abstract}
Staging full-scale plays in Italian with French non-specialist students, following a predominantly product-oriented theatrical approach, may prove very beneficial in terms of students' commitment and of intercultural learning. Students' involvement in the staging project and their motivation in learning can be further stimulated by the staging of comic plays. As emphasized in this paper, the social approach to the comic which Henri Bergson proposes in Laughter (1900) offers many useful hints which can be exploited by teachers interested in teaching foreign languages through theatre practice. The paper also deals with the teaching of paralinguistic features, which is particularly interesting for students to explore in connection with the Italian comic tradition and the staging of full-scale plays. ${ }^{1}$
\end{abstract}

\section{Introduction}

This paper is based on my experience of teaching Italian as a foreign language, but also of stage directing and playwriting. It deals in particular with the staging of full-scale plays with students and discusses the assets of teaching foreign languages through the comic, which is especially valuable for introducing learners to the features of nonverbal communication. The title of the paper refers to a comic device often linked to gender issues, which I have made use of in several staged plays. The "stuffed pants" device involves the simulation of a large apotropaic sexual organ, or changing someone's appearance in other grotesque ways.

I have been staging full-scale comic plays in Italian for four years in the Department of Applied Linguistics at the University of Grenoble, working with groups of ten to fifteen non-specialist students (i.e. students who are not majoring in Modern Languages), whose proficiency in the target language ranges from intermediate to advanced level (for further details, see Fonio \& Genicot 2011). In this period, I have worked on different types of projects,

\footnotetext{
${ }^{1}$ I am grateful to Fiona Dalziel for her language revisions.
} 
and in particular on writing and staging devised theatre with my students, on adapting novels or movies for the stage (in collaboration with students and playwrights), or on proposing more classical productions of ready-to-stage plays - always with the stamp of comedy!

\section{Why full-scale plays?}

The first question I would like to discuss in the paper is the following: why is staging full-scale plays with foreign language students an effective way, both for them and for me, to enjoy an intercultural experience, which is useful for them to enhance their linguistic, sociolinguistic and pragmatic competences (Council of Europe 2001: 13-14)?

This question refers to a well-known debate, summarized by Moody (2002). He underlines that "process-oriented" and "product-oriented" approaches to drama teaching differ in terms of their respective goals:

On the one hand, a process-oriented approach tends to focus on the dramatic medium itself, in which the negotiation, rehearsal, and preparation for a more informal, or improvisational, in-class dramatic representation becomes the focus for language learning. On the other hand, a productoriented approach emphasizes the final staging of the students' public performance, wherein the concluding dramatic realization in front of an audience is viewed as one of the primary goals of the learning experience. (Moody 2002: 135-136)

The main advantage of a process-oriented approach to foreign language drama teaching is that of an "open learning environment" (ibid.: 138), which is not based primarily on literacy and text-related activities. As regards the product-oriented approach to foreign language learning through theatre practice, its main goal is to stage sketches or full-scale plays with students for public performance.

Process-oriented drama teaching partisans claim that public performances partially obscure the goals of teaching and learning through drama, because the learners' attention tends to focus on the final performance. My experience so far has persuaded me that public performances are, on the contrary, a powerful stimulus for students to maintain their attention and concentration. Moreover, activities related to the various practical aspects of the staging process - from the playwriting or play adaptation to costumes and props, set and lightning design - correspond closely to the communicative and action-oriented approach of the Common European Framework of Reference (CEFR), upon which many foreign language syllabi are now based (see Fonio \& Genicot 2011). In fact, the action-oriented approach of the CEFR cries out for strongly task-oriented language teaching and learning activities, and the different steps of the staging process offer the teacher the opportunity to propose to students simple task-divisions. In addition to the tasks related to the staging process, which are intended to be accomplished in a participative way by pairs or small 
groups of students, the production of a staged play at the end of each academic year allows my students to perform in Italian and French festivals. On these occasions, students are actively involved in practical matters related to travel and accommodation and to the pre- and post-event communication plans. Most of these tasks must be performed in Italian, which is both a challenging and an enriching experience for the students.

The interdisciplinary learning connected to the staging process of a play is probably one of the greatest benefits of adopting a product-oriented approach to theatre practice in foreign language pedagogy. During the different steps of the theatrical project, students have to familiarise themselves with, and to be able to present to others, a rich variety of textual typologies in the target language, either through oral or written activities. Through this documentary research, the learners' autonomy is fostered during the study phase of the staging process. They show strong motivation in undertaking autonomous documentary research: the most interesting of their original texts are used as complements to the staging process or incorporated into the play, and almost every student wants the script of the play to be his or her own. This approach to documentary research is further enriched by the continuous exchanges students have with the teacher as well as with their classmates, which gives birth to a constant dynamic of discussion, negotiation and purposeful communication (for the case study of a similar pedagogical process, see Ryan-Scheutz \& Colangelo 2004). The scheduling of public performances is certainly an incentive for the students to accomplish the various activities effectively and on time. If students feel that their research into and elaboration of appropriate materials result in a successful staging process, their commitment to the whole project will increase and this in turn will result in a richer script.

Finally, from the teacher's perspective, the staging process may be conceived as a collective macro-task that includes many individual or small-group microtasks, and task performance is perfectly in line with the communicative approach to foreign language learning. Moreover, students' reports show how strongly learners have been impressed by performing collective creations produced by each member of the group through his or her own personal contribution.

\section{Why the comic?}

The second question this paper focuses on is why the comic, especially if combined with the staging of full-scale plays, constitutes a powerful vehicle to achieve intercultural learning goals?

Almost every teacher practising the staging of comic plays or sketches with students would agree with the paradox that the strong desire, and sometimes the anxiousness that students feel in their yearning to make the future audience laugh, introduces a high degree of seriousness in classroom activities from the beginning of the staging project. Even if it is the first theatrical experience for most of the students, they immediately grasp the importance of maintaining seriousness during rehearsals and performances, as if they were naturally 
conscious of the social function of the comedy-monger. This tendency is probably connected to one's everyday life: it is in fact quite common to experience the varying effect obtained when, in telling a joke in front of an audience, either we are able to keep our role until the dénouement, or we start laughing. In the second case, we, as the masters of ceremony, are not able to wait until the time is right before allowing ourselves to laugh, and thus we miss the chance to achieve the most valuable effect, because timing is one of the most important parameters in the comic.

This is particularly evident while performing for the first time in front of a large audience, because seeing and/or hearing the audience laugh when one is telling a joke or making funny movements on stage - not forgetting that being in disguise always enhances the comic effect - gives the performers immediate proof of efficacy. My students have always reacted in a very positive way to "hot" audiences and to the strong emotions they feel every time the show becomes somehow interactive. They even experienced situations where they had to stop acting until the audience stopped laughing. Performing in a foreign language is an even more powerful challenge to one's self-confidence, especially in the case of novice students actors.

When staging comic plays with a strong textual component, seriousness and concentration have to be maintained throughout the whole staging project, and not only during public performances. All thorough work on text-centred comic theatre, in particular in a foreign language, begins with a meticulous close reading of the script, because a deep understanding of the text is necessary in order to perform it with accuracy both on a literal and expressive level. As the comic is a deeply rooted cultural form, and humour is often based on cultural mechanisms, the sociocultural reading of the script needs to be particularly accurate.

If "situation comedy" kinds of tricks and devices are of particular interest and use in a pedagogical context, the Italian theatrical tradition also offers an inexhaustible source of comic characters and jokes. The heritage of commedia dell'arte in fact forms the basis for a great amount of modern and contemporary comedy. A very important feature that these culturally different traditions have in common is that both situation comedy and commedia dell'arte very often use stereotyped plots and characters. They both also have the tendency to propose exaggeratedly stereotyped characters.

I am basing some of the remarks contained in this section on Henri Bergson's philosophical essay Laughter (1900). The idea of using Bergson's framework in order to interpret the comic and laughter (which is, in Bergson's opinion, the symptom of the comic) as social phenomena is in fact particularly stimulating from a pedagogical point of view. Moreover, Bergson's theory of laughter, which is close to Sigmund Freud's interpretations of humour, is a cornerstone in the definition of the comic, and his conclusions are to be found in other classic books on the topic, including Johan Huizinga's Homo ludens (1938).

In order to conduct an enquiry into the mechanisms of laughter as a socially based device against excesses of individualism, Bergson proposes a strong 
relationship between laughter and human vices, physical or moral defects (clumsiness, greed etc.), passions (sexual desire, jealousy etc.) - which is particularly apparent if we think of Molière's comedies, for instance. But, and this is a fundamental point in Bergson's analysis, it is important, on the one hand, to try to push these characteristics to the extreme while performing, and on the other hand to do it in a natural way, in an imitable Aristotelian way, in order not to prevent or inhibit, but on the contrary to stimulate laughter, because: "A deformity that might become comic is a deformity that a normally built person could successfully imitate" (Bergson 1900: 18). A mocking imitation which maintains verisimilitude is, in other words, essential to cause laughter, as otherwise the dominant feeling of an audience would be (com)passion, and not the "intelligence" (ibid.: 11) which is necessary to laugh at a situation.

This kind of "imitative grotesqueness" is often enhanced, according to Bergson, through disguise: "A man in disguise is comic. A man we regard as disguised is also comic. So, by analogy, any disguise is seen to become comic, not only that of a man, but that of society also, and even the disguise of nature" (ibid.: 26). It would thus be legitimate to affirm that the comic is able to show an entire society in disguise:

As we are both in and of [society], we cannot help treating it as a living being. Any image then, suggestive of the notion of a society disguising itself, or of a social masquerade, so to speak, will be laughable. Now, such a notion is formed when we perceive anything inert or stereotyped, or simply ready-made, on the surface of living society. (ibid.: 27)

Some examples taken from our 2011 and 2012 productions will illustrate the importance of those components of the comic in foreign language teaching and learning. The play we staged in 2011, Cercasi marito pensionato... importante che muoia subito ("Wanted: retired husband... the most important is that he dies soon") was an adaptation of a play written by the young Italian playwright Giovanni Allotta. Last year play, La villa dell'assassinio ovvero Dialogo di un assistente alla regia con la sua anima ("The murder mansion, or Dialogue of an assistant director with his soul") was co-written by me and Chiara Piola Caselli.

Both plays contain many "grotesquely stereotyped" characters related to the different milieux they portray. Cercasi marito... depicts a very traditional and religious Sicilian country world, in which we can find, amongst other characters, a hunchback doctor who only listens to money talk, an equally greedy middle-aged woman and a gloomy homosexual undertaker. La villa dell'assassinio is a parody of the professional world of theatre, with a frustrated assistant director, neurotic theatre stars in decline and young rampaging soap opera and television wannabes.

During the writing/adapting and the staging process, we worked on developing and pushing to the extreme the characterisation of the grotesque. This exaggeration was pursued with a precise pedagogical aim, i.e. to prevent excesses in the identification process with the grotesque or stereotyped characters through a series of improvisations and other activities based on 
the authentic materials (videos, newspapers articles, pictures, extracts from literature) collected by the students during their research. These excesses are particularly dangerous for shy students and for those who are taking part in their first theatrical experience and who are already rather clumsy on stage. A complete identification process would in fact result in a less credible performance both for the actors and for the audience. Bergson helps us on this point in recalling that "natural or imitated clumsiness" is probably the most frequent source of laughter for an audience, and if we think of the repertoire of fixed expressions (often imposed by masks, by the way), stiffness and automatisms in movements and attitudes that commedia dell'arte offers we will immediately acknowledge the importance of helping students play the characters' clumsiness instead of focusing on their own uneasiness.

Moreover, novice students-actors tend to break down completely if they temporarily lose the perception of being on stage "in role", or worse if they do not seize the difference between being on- and off-stage. That is why working with the "exaggeratedly grotesque" allows one to maintain a safe distance between the actors and their characters. This distance is perfectly perceived by the audience, who are thus allowed to enter quite easily into the fictional framework of the play as soon as it is understood that the actors are exaggerating the grotesque on purpose. Turning stage fear - which is quite a common sentiment - into stage frenzy through the creation of exaggeratedly grotesque but convincing characters is thus necessary because only a fully committed actor is able to make an audience laugh during a public performance. Half-convincing characters tend in fact to show, rather than to hide, the weaknesses of amateur actors, while strongly pushing on the accelerator of the exaggeratedly grotesque allows audiences to believe the unbelievable.

Let us think of swearing and bad words for instance. The students instinctively react with prudery over the uttering of swear words on stage, in front of their parents, boyfriends and girlfriends, university pals and teachers. I have often had this kind of reaction early in the staging project, when, normally, the script is already there but the characters have not been sufficiently worked on. In order to enable the students to free their minds and speech, I usually deploy a series of exercises geared to developing the respective character's exaggeratedly grotesque nature. These exercises entail, for instance, creating a scapegoat that is then successfully reintegrated into the group. Afterwards, the students are able to perform their characters by pushing excess to its limits.

In addition to what has been mentioned above, another good reason for having students engage in comic theatre is that it is one of the most powerful ways to create social cohesion, both between the students who are staging the same play and between the students and the audience, as we have just seen. According to Bergson, and what everyone knows from their daily experience, laughter is an inclusive dynamic: you don't join in laughing if you don't feel like you are part of the "laughing community".

When performing in public, one of the most immediate ways to create, or to check, the existence of a sense of community with the audience is the use 
of asides (i.e. remarks addressed to the audience but not to be heard by the other characters of the play). For example in La villa dell'assassinio the assistant director often makes use of asides to show the audience his real opinions about the other characters of the play, which gives way to very funny wordplay, such as: "Ecco Moreno Badedas, accompagnato dalla sua dolce metà ... [A parte] metastasi" ("And here is Moreno Badedas, accompanied by his sweetheart ... [Aside] metastasis"). Also in our adaptation of Cercasi marito... asides were quite frequent, as they were normally used to deform with parody other characters' words, as in "Seychelles" misshaped in "sei ascelle" ("six armpits").

Wordplay is obviously only one of the comic forms which it is possible (and probably easier) to exploit for a pedagogical aim. "Comedy of situations" and "comedy of characters" are both important when working on Italian comic theatre, as we have seen, and I am convinced that they are also amongst the most immediate ways to convey cultural contents. For example, in adapting Cercasi marito... we used comedy of situations to render ridiculous the mournfully serious atmosphere of death rituals popular in the Italian countryside. So, the undertaker who is supposed to take away the dead body of the merry widow's husband tries to make as much money as possible out of the woman's conformism, which obliges her to honour the dead through luxurious paraphernalia; in particular he describes different kinds of coffins as if referring to the range of optional devices for cars (which also gives the teacher the chance to work on technical vocabulary). In addition to the lexical richness which wordplay allows the students to experiment with, the staging of culturally-rooted comedy plays also gives the learners access to the extraordinarily ancient and successful tradition of this genre of Italian theatre. Staging an Italian comedy play nowadays, especially from a pedagogical perspective, requires contextualising the text in its complex literary and cultural tradition, which can be accomplished through the aforementioned documentary research undertaken by the students. In order to understand specific cultural contents when staging and acting a play, students have to engage in activities which allow them not only to focus on oral production and rendition, but also to enhance listening and reading of documents inherent to specific topics related to the cultural contents of the chosen play (for example improvisation exercises starting from videos based on the use of dialects as a social marker and as a diaphasic variety in Italian conversations, or on idiomatic linguistic features and professional jargons). Thus, devising plays with the students through the reading of literary texts and improvisation activities (as we did in 2008 starting from the novel Mai sentita cosi bene by Rossana Campo) is also helpful in enhancing their cultural awareness. The same could be said for less complex tasks related to the constant discussions and exchanges required during the staging process (as described above).

The cultural importance of stereotypes should not be forgotten either. European cultural history and civilisation show that, when it comes to stereotypes, every one of us refers to national stereotypes, or at least to cultural a priori strictly connected to the image that every representative of a culture 
possesses of the other, or the others. That is why we, as teachers, are able to transmit to students, precisely by the fact of working on, and with stereotypes, rich contents in terms of cultural features. Working with stereotypes, and in particular with exaggerated and grotesque ones, greatly contributes both to transmitting cultural contents to students, and overcoming neophytes' stage fear. For example, in 2011 we worked with stereotypes related to masculine and feminine issues in Southern Italy, and we also had the chance to discuss the topic with the playwright himself. Giovanni Allotta led a three-day workshop with the students in Grenoble, that was very useful in order to understand and to contextualise stereotypes. He allowed the students to enter the playwriting process showing them how his exaggeratedly grotesque characters originated from "normal" people he met in his daily life, and reproduced the same process of "deforming everyday life" with the help of the students. These activities led them to understand the deep relations which connect real life and theatrical creativity through the work on stereotypes.

Dealing with this kind of exaggerated and grotesque comic theatre obviously creates a delicate balance between uses and abuses of clichés and stereotypes. If we consider, for example, commedia dell'arte and all its successors in the Italian comic tradition, from Carlo Goldoni to Dario Fo, it would be easy to recognise a series of (stereo-)typical comic characters, whose gestures, crystallized expressions etc. should be studied very carefully every time one tries to re-enact plays which are located in the same theatrical current. It is dangerous, in fact, to approach verbal and nonverbal stereotypes in a thorough way while working with learners who have a rather distanced and often indirect relationship with the foreign country and its society. The risk in these cases is to contribute to creating a distorted image of the target culture. It is therefore very important to offer counterexamples and to contextualise stereotypes in order not to lose the extraordinary cultural richness that stereotypes convey.

\section{The comic as a way to teach nonverbal features of language}

If we look at the Italian theatrical tradition, both from a stage-oriented and from a pedagogical perspective (as in Frassica 2009), a quick glance at its history from commedia dell'arte onwards will reveal the remarkable role played in it by mimic comic, or by comedy which combines wordplay and mimicry.

The culturally rooted nonverbal component of Italian comic theatre provides a way of introducing paralinguistic features into the foreign language classroom. The acquisition of nonverbal competences is in fact closely connected to fluency in oral communication, because the mastering of paralinguistic traits helps students to emphasise their speech, but also to bridge linguistic gaps as regards words and expressions. Moreover, proficiency in nonverbal traits of the foreign language distinguishes culturally aware learners from those who are merely exposed to bookish oriented teaching. 
So, if passive paralinguistic knowledge is essential so as to acquire "intercultural awareness" (Culham 2002: 96), an active competence in nonverbal traits allows learners to accompany, complete, enhance meaning, because gestures are a powerfully iconic way to convey meaning. In the Italian cultural tradition, touching is, in particular, one of the paralinguistic parameters which is more difficult for non-native speakers to understand and to incorporate into oral communication (and quite often teachers tend to forget that kinesics is strictly connected to paralinguistics).

In my experience, staging physically engaging comic plays is an easy way to make students aware of the gestural patterns of communication in the foreign language, and careful work on dramatic and theatrical techniques should never neglect the nonverbal component of the target language. It is important to propose activities which allow one to introduce a progression in nonverbal features, from eye contact to more articulated sequences of movements, also in order to help students to memorise paralinguistic traits. Moreover, playing with gestures often means, for non-native speakers, risk-taking at a higher degree than simply performing a script which has been memorised.

The emotional tension that is often generated by bodily engaging exercises also helps students in finding unexpected and unpredictable (para-)linguistic skills in themselves, or in creating them in ways that make sense. This is particularly evident when exercises on paralinguistic features are proposed in a dialogical form, for example in pairs or small groups, since the dynamics of speaking and listening through the nonverbal (Culham 2002: 109) engages students in an effort to make their messages understandable to their peers.

This is particularly useful when a full-scale play is to be staged, because gestures form a pattern which is parallel and complementary to the text, and which needs to be memorised with the same accuracy. That is why I have always asked my students to analyse theatrical texts as if there existed another text running parallel to the spoken lines, which describes the paralinguistic traits of each character.

In conclusion, staging full-scale comic plays with students not only enhances motivation to learn different aspects of the target language, and in particular paralinguistic features, but it is also a form of learning which is deeply rich in cultural contents.

\section{Bibliography}

Bergson, Henri (1900): Laughter. An Essay on the Meaning of the Comic, Rockville (Maryland): Arc Manor, 2008 (English translation by Cloudesely Brereton and Fred Rothwell)

Council of Europe (2001): Common European Framework of Reference for Languages (CEFR): Learning, Teaching, Assessment. Online English version available at: 
http://www.coe.int/t/dg4/Iinguistic/Source/Framework_EN.pdf (last accessed 10/12/2012)

Culham, Cameron R. (2002): Coping with Obstacles in Drama-Based ESL Teaching: A Nonverbal Approach. In: Bräuer, Gerd (ed.): Body and Language. Intercultural Learning Through Drama. Westport (Connecticut), London: Ablex Publishing, 95-112

Fonio, Filippo; Genicot, Geneviève (2011): The Compatibility of Drama Language Teaching and CEFR Objectives - Observations on a Rationale for an Artistic Approach to Foreign Language Teaching at an Academic Level. In: Scenario 2, 71-84

Frassica, Pietro (2009): Authors, Texts, and Innovative Movements: An Overview of the Italian Theatrical Canon. In: Marini-Maio, Nicoletta; Ryan-Scheutz, Colleen (eds.): Set the Stage! Teaching Italian Through Theater. Theories, Methods, and Practices, New Haven, London: Yale University Press, 27-49

Moody, Douglas J. (2002): Undergoing a Process and Achieving a Product: A Contradiction in Educational Drama? In: Bräuer, Gerd (ed.): Body and Language. Intercultural Learning Through Drama. Westport (Connecticut), London: Ablex Publishing, 135-159

Ryan-Scheutz, Colleen; Colangelo, Laura M. (2004): Full-Scale Theater Production and Foreign Language Learning. In: Foreign Language Annals $37 / 3,374-385$ 